\title{
Enhancement of ATC by Optimal Allocation of TCSC and SVC by Using Genetic Algorithm
}

\author{
Sandhya Rani Bhooma, Suresh Regatti \\ Student in EEE Department Assistant Professor in EEE Department Sri Venkateshwara Engineering College \\ ,Suryapet
}

\begin{abstract}
This paper proposes Improving of ATC is an important issue in the current de-regulated environment of power systems. The Available Transfer Capability (ATC) of a transmission network is the unutilized transfer capabilities of a transmission network for the transfer of power for further commercial activity, over and above already committed usage. Power transactions between a specific seller bus/area and a buyer bus/area can be committed only when sufficient ATC is available. Transmission system operators (TSOs) are encouraged to use the existing facilities more effectively to enhance the ATC margin. Heavily loaded circuits and buses with relatively low voltages can limit ATC usually. It is well known that FACTS technology can control voltage magnitude, phase angle and circuit reactance. Using these devices may redistribute the load flow, regulating bus voltages. Therefore, it is worthwhile to investigate the impact of FACTS controllers on the ATC. In this thesis focuses on the evaluation of the impact of TCSC and SVC as FACTS devices on ATC and its enhancement during with and without line outage cases. In a competitive (deregulated) power market, optimal the location of these devices and their control can significantly affect the operation of the system and will be very important for ISO.
\end{abstract}

Keywords: FACTS devices, Available Transfer Capability, TCSC, Genetic Algorithm

\section{Introduction}

Deregulation and restructuring of the electric power industry is occurring in many nations throughout the world. Competitive marketplace is established for market participants who will encounter many new problems in market operation and regulation. In the US, the Federal Energy Regulatory Commission (FERC) gave the right of nondiscriminatory open access to the transmission facilities to all market participants. It is (ATC) information be made available on a publicly Accessible Open Access Same-time Information required that so-called Available Transfer Capability System (OASIS) [1]. ATC is defined by North American Electric Reliability Council (NAERC) as a measure of the transfer capability in the physical transmission network for transfers for future commercial activities over already committed uses. The calculation of ATC involves three components: Total Transfer Capability (TTC), Transmission Reliability Margin (TRM) and Capacity Benefit Margin (CBM) [1]. Based on a base case, TTC is the largest flow increase between the selected source/sink transfer without any line thermal overload, violation of voltage limits, voltage collapse or transient instability. The calculation of TTC is the major burden during the calculation of ATC. TTC is dependent on many factors, such as the base case of system operation, system operation limits, network configuration, specification of contingencies, etc. FACTS devices, which can provide direct and flexible control of power transfer, can be very helpful in the operation of competitive power markets. How to use FACTS to control power flow control to improve power transfer capability so that it enhance the power market competitiveness is an active research area. The compensation scheme of TCSC has been widely accepted as a solution for the limitation created by generation and transmission systems. With proper control of FACTS devices, TTC may be adjusted significantly. Thyristor Controlled Series Compensator (TCSC) as an effective series compensation device can be used for this purpose. In this paper the effectiveness of TCSC to enhance TTC at steady state is investigated. The location and the amount of compensation will have to be determined in power flow control problems. Several studies have evaluated the function of series compensators using objective sensitivities for the predetermined locations or parameters of the device required [2,3]. Genetic Algorithms (GAs) are probabilistic heuristic search procedures based on natural genetic system. It uses probabilistic transition rules, not deterministic rules. GA is highly multi-direction, pmallel and rather robust method in searching global optimal solution of complex optimization problems. By using random choice as a tool in the search process, it possesses the advantage to help preventing the algorithm getting stuck in a local minimum. Power system researchers have implemented the technique broadly in recent years [4]. This paper explores the application of Genetic Algorithm (GA) to determine the location and the amount of compensation of TCSC for enchanting TTC. A simplified TTC has been used as an index to evaluate the impacts of TCSCS in competitive power markets and then a real Genetic Algorithm is developed to explore the allocations and the amount of compensation of one and two TCSCS in a system. This paper is organized as follows. Section 2 discusses the calculation of Total Transfer 
Capability. TCSC modeling is outlined in Section 3. Section 4 presents the procedure for constructing Genetic Algorithm and applying different techniques for GA operators. Studies on the IEEE 14-bus to demonstrate the implementation of proposed algorithm are presented in Section 5.

\section{Available Transfer Capability}

Mathematically, ATC is defined as [4, 5], the Total Transfer Capability (TTC) less the Transmission Reliability Margin (TRM), less the Capacity Benefit Margin (CBM) and the sum of existing transmission commitments (TC) which includes retail customer service. Transmission Reliability Margin (TRM) $[4,5]$ is defined as that amount of transmission transfer capability necessary to ensure that the interconnected transmission network is secure under a reasonable range of uncertainties in system conditions. Capacity Benefit Margin (CBM) [4, 5] is defined as that amount of transmission transfer capability reserved by load serving entities to ensure access to generation from interconnected systems to meet generation reliability requirements.

$\mathrm{ATC}=\mathrm{TTC}-\mathrm{TRM}-\mathrm{CBM}-\mathrm{TC}$

In this paper, the margins such as TRM and CBM are not considered. Therefore ATC here can be expressed as: $\mathrm{ATC}=\mathrm{TTC}-\mathrm{TC}$

The procedure proposed involves the method based on multiple load flow runs AC load flow for each increment of transaction between an interface and checks whether any of the operating conditions such as line flow limit or bus voltage limit is violated. The minimum out of the two critical transaction values is taken as the TTC for the system in that condition.

\section{Algorithm for ATC Calculation Using CPF}

(i) a) Read the system line data and bus data

System data: From bus, To bus, Line resistance, Line reactance, half line charging, Off nominal turns ratio, maximum line flows.

Bus data: Bus no, Bus type, Pgen, Qgen, PLoad, QLoad, Pmin, Pmax, Vsp shunt capacitance data.

b) Cal Pshed(i), Qshed(i), for $\mathrm{i}=1$ to $n$

Where Pshed(i)= Pgen(i)-PLoad(i)

Qshed(i) $=$ Qgen(i) - QLoad $(i)$

c) Form Ybus using sparsity technique

(ii) a) iter $=1$ iteration count

b) Set $\left|\Delta P_{\max }\right|=0$ and $\left|\Delta Q_{\max }\right|=0$

c) Calculate $\mathrm{P}_{\text {cal }}(\mathrm{i})=\sum_{q=1}^{n}\left|V_{i}\right|\left|V_{q}\right|\left|Y_{i q}\right| \cos \left(\delta_{i q}-\theta_{i q}\right)$

$\mathrm{Q}_{\text {cal }}(\mathrm{i})=\sum_{q=1}^{n}\left|V_{i}\right|\left|V_{q}\right|\left|Y_{i q}\right| \sin \left(\delta_{i q}-\theta_{i q}\right)$

d) Calculate

$\mathrm{P}(\mathrm{i})=\mathrm{P}_{\text {shed }}(\mathrm{i})-\mathrm{P}_{\text {cal }}(\mathrm{i})$

$\mathrm{Q}(\mathrm{i})=\mathrm{Q}_{\text {shed }}(\mathrm{i})-\mathrm{Q}_{\text {cal }}(\mathrm{i})$ fori $=1$ to $\mathrm{n}$

Set $P_{\text {slack }}=0.0, Q_{\text {slack }}=0.0$

e) Calculate $\left|\Delta P_{\max }\right|$ and $\left|\Delta Q_{\max }\right|$ form $[\Delta \mathrm{p}]$ and $[\Delta \mathrm{Q}]$ vectors

f) Is $\left|\Delta P_{\max }\right| \leq \epsilon$ and $\left|\Delta Q_{\max }\right| \leq \epsilon$

If yes go to step (vii), problem converged case

iii)Form Jacobian elements

a) Initialize $\mathrm{A}[\mathrm{i}][\mathrm{j}]=0$, for $\mathrm{i}=1$ to $2 \mathrm{n}+2, \mathrm{j}=1$ to $2 \mathrm{n}+2$

$H_{p p}=\frac{\partial P_{p}}{\partial \delta_{p}}=-Q_{p}-B_{p p}\left|V_{p}\right|^{2}$

b) Form diagonal elements for $\mathrm{i}=1$ to $\mathrm{n}$

$N_{p p}=\frac{\partial P_{p} \cdot\left|V_{p}\right|}{\partial V_{p}}=P_{p}+G_{p p}\left|V_{p}\right|^{2}$

$M_{p p}=\frac{\partial Q_{p}}{\partial \delta_{p}}=P_{p}-G_{p p}\left|V_{p}\right|^{2}$

$L_{p p}=\frac{\partial Q_{p}\left|V_{p}\right|}{\partial V_{p}}=Q_{p}-B_{p p}\left|V_{p}\right|^{2}$

c)Formation of off diagonal elements 


$$
\begin{aligned}
& H_{p q}=\frac{\partial P_{p}}{\partial \delta_{q}}=\left|V_{p}\right|\left|V_{q}\right|\left(G_{p q} \sin \delta_{p q}-B_{p q} \cos \delta_{p q}\right) \\
& N_{p q}=\frac{\partial P_{p}\left|V_{q}\right|}{\partial V_{q}}=\left|V_{p}\right|\left|V_{q}\right|\left(G_{p q} \cos \delta_{p q}+B_{p q} \sin \delta_{p q}\right) \\
& M_{p q}=\frac{\partial Q_{p}}{\partial \delta_{q}}=-N_{p q} \\
& L_{p q}=\frac{\partial Q_{p}\left|V_{q}\right|}{\partial V_{q}}=H_{p q}
\end{aligned}
$$

d) Modification of Jacobian elements for slack bus and generator buses For slack bus $\mathrm{H}_{\mathrm{pp}}=10^{20}, \mathrm{~L}_{\mathrm{pp}}=10^{20}$ For PV buses $\mathrm{L}_{\mathrm{pp}}=10^{20}$

e) Form right hand side vector

$\mathrm{B}[\mathrm{i}]=\Delta \mathrm{P}[\mathrm{i}], \mathrm{B}[\mathrm{i}+\mathrm{n}]=\Delta \mathrm{Q}[\mathrm{i}]$

for $\mathrm{i}=1$ to $\mathrm{n}$ Jacobian correction mismatch vector

(iv) Use Gauss-elimination method for solving

$[A][\Delta X]=[B]$ Update the phase angle and voltage magnitudes for $\mathrm{i}=1$ to $\mathrm{n}$

$\delta_{i}=\delta_{i}+\Delta X_{i}$

$V_{i}=V_{i}+\left\{\Delta X_{i+n}\right\} V_{i}$

(v)One iteration over Advance iteration count iter=iter+1 If (iter>itermax) go to step (ii) (b) Else go to step (vi).

(vi) NR is not converged in "itermax" iterations

(vii)NR is converged in 'iter' iterations calculate

a. Line flows b. Bus powers, Slack bus power.

c. Print the converged voltages, line flows and powers.

(viii) Read the sending bus (seller bus) $m$ and the receiving bus (buyer bus) $n$.

(ix) Assume some positive real power injection change $\Delta \operatorname{tp}(=0.1)$ i.e. $\lambda$-factor at seller bus- $m$ and negative injection $\Delta \operatorname{tp}(=0.1)$ i.e. $\lambda$-factor at the buyer bus- $n$ and form mismatch vector.

(x) Repeat the load flow (i.e., from steps (ii) to (vii)) and from the new line flows check whether any of the line is overloaded. If yes stop the repeated power flow else go to (ix).

(xi)The maximum possible increment achieved above base-case load at the sink bus is the ATC.

\section{Modeling of TCSC}

Transmission lines are represented by lumped $\pi$ equivalent parameters. The series compensator TCSC is simply a static capacitor/reactor with impedance jxc [6]. Fig. shows a transmission line incorporating a TCSC.

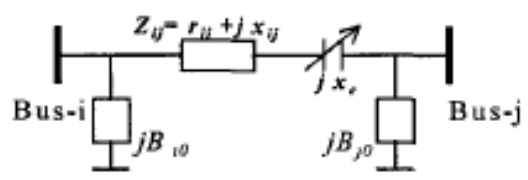

Fig: Equivalent circuit of a line with TCSC

Where $\mathrm{X}_{i j}$ is the reactance of the line, $\mathrm{R}_{\mathrm{ij}}$ is the resistance of the line, $\mathrm{B}_{\mathrm{io}}$ and $\mathrm{B}_{\mathrm{jo}}$ are the half-line charging susceptance of the line at bus-i and bus-j. The difference between the line susceptance before and after the addition of TCSC can be expressed as:

$$
\begin{gathered}
\Delta y_{i j}=y_{i j}^{\prime}-y_{i j}=\left(g_{i j}^{\prime}+j b_{i j}^{\prime}\right)-\left(g_{i j}+j b_{i j}\right) \\
g_{i j}=\frac{r_{i j}}{\sqrt{r_{i j}^{2}+x_{i j}^{2}}}, b_{i j}=-\frac{x_{i j}}{\sqrt{r_{i j}^{2}+x_{i j}^{2}}} \\
g_{i j}^{\prime}=\frac{r_{i j}}{\sqrt{r_{i j}{ }^{2}+\left(x_{i j}+x_{c}\right)^{2}}}, b_{i j}^{\prime}=-\frac{x_{i j}+x_{c}}{\sqrt{r_{i j}^{2}+\left(x_{i j}+x_{c}\right)^{2}}}
\end{gathered}
$$

After adding TCSC on the line between bus i and bus $\mathrm{j}$ of a general power system, the new system admittance matrix $\mathrm{Y}_{\text {bus }}$ can be updated as 
$Y_{\text {bus }}^{\prime}=Y_{\text {bus }}+\left[\begin{array}{ccccccc}0 & 0 & 0 & \ldots & 0 & 0 & 0 \\ 0 & \Delta y_{i j} & 0 & \ldots & 0 & -\Delta y_{i j} & 0 \\ 0 & 0 & 0 & \ldots & 0 & 0 & 0 \\ \ldots & \ldots & \ldots & \ldots & 0 & \ldots & 0 \\ 0 & 0 & 0 & \ldots & 0 & 0 & 0 \\ 0 & -\Delta y_{i j} & 0 & \ldots & 0 & \Delta y_{i j} & 0 \\ 0 & 0 & 0 & \ldots & 0 & 0 & 0\end{array}\right]$ row $-i$

Algorithm for Newton Raphson power flow Using TCSC

(a) Read the system line data, bus data and TCSC data

Line data: From bus, To bus, line resistance, line reactance, half-line charging susceptance and off nominal tap ratio.

Bus data: Bus no, Bus itype, $\mathrm{P}_{\text {gen, }}, \mathrm{Q}_{\text {gen, }} \mathrm{P}_{\text {load, }} \mathrm{Q}_{\text {load, }}$ and shunt capacitor data.

TCSC data: TCSC Line no., variable reactance $\left(\mathrm{X}_{\mathrm{C}}\right)$

(b) Form $Y_{\text {bus }}$ using sparsity technique.

(c) Modify the $Y_{\text {bus }}$ elements with the value of TCSC reactance.

The difference between the line susceptance before and after the addition of TCSC between bus-i and bus- $j$ can be expressed as:

$$
\begin{aligned}
& \Delta y_{i j}=y_{i j}^{\prime}-y_{i j}=\left(g_{i j}^{\prime}+j b_{i j}^{\prime}\right)-\left(g_{i j}+j b_{i j}\right) \\
& g_{i j}=\frac{r_{i j}}{\sqrt{r_{i j}{ }^{2}+x_{i j}^{2}}}, b_{i j}=-\frac{x_{i j}}{\sqrt{r_{i j}^{2}+x_{i j}^{2}}} \\
& g_{i j}^{\prime}=\frac{r_{i j}}{\sqrt{r_{i j}{ }^{2}+\left(x_{i j}+x_{c}\right)^{2}}}, b_{i j}^{\prime}=-\frac{x_{i j}+x_{c}}{\sqrt{r_{i j}^{2}+\left(x_{i j}+x_{c}\right)^{2}}}
\end{aligned}
$$

Modification in diagonal elements as $Y_{p p}(i)=Y_{p p}(i)+\Delta y_{i j}$

Modification in off-diagonal elements as $y \operatorname{line}(i j)=y$ line $(i j)-\Delta y_{i j}$

2.(a) $\mathrm{k}_{1}=1$ iteration count

(b)Set $\left|\Delta P_{\max }\right|=0.0,\left|\Delta Q_{\max }\right|=0.0$

(c)Cal $\mathrm{P}_{\text {shed }}(\mathrm{i}), \mathrm{Q}_{\text {shed }}(\mathrm{i})$, for $\mathrm{i}=1$ to $\mathrm{n}$.

Where $P_{\text {shed }}(\mathrm{i})=\mathrm{P}_{\text {gen }}(\mathrm{i})-\mathrm{P}_{\text {load }}(\mathrm{i})$

$\mathrm{Q}_{\text {shed }}(\mathrm{i})=\mathrm{Q}_{\text {gen }}(\mathrm{i})-\mathrm{Q}_{\text {load }}(\mathrm{i})$

(d)Calculate $\mathrm{P}_{\text {cal }}(\mathrm{i})=\sum_{q=1}^{n}\left|V_{i}\right| V_{q}|| Y_{i q} \mid \cos \left(\delta_{i q}-\theta_{i q}\right)$

$$
\mathrm{Q}_{\text {cal }}(\mathrm{i})=\sum_{q=1}^{n}\left|V_{i}\right|\left|V_{q} \| Y_{i q}\right| \sin \left(\delta_{i q}-\theta_{i q}\right)
$$

(e) Calculate $\quad \Delta \mathrm{P}(\mathrm{i})=\mathrm{P}_{\text {shed }}(\mathrm{i})-\mathrm{P}_{\text {cal }}(\mathrm{i})$

$\Delta \mathrm{Q}(\mathrm{i})=\mathrm{Q}_{\text {shed }}(\mathrm{i})-\mathrm{Q}_{\text {cal }}(\mathrm{i}) \quad$ for $\mathrm{i}=1$ to $\mathrm{n}$

Set $\Delta \mathrm{P}_{\text {slack }}=0.0, \Delta \mathrm{Q}_{\text {slack }}=0.0$,

(f) Calculate $\left|\Delta P_{\max }\right|$ and $\left|\Delta Q_{\max }\right|$ form $[\Delta \mathrm{p}]$ and $[\Delta \mathrm{Q}]$ vectors

(g)Is $\left|\Delta P_{\max }\right| \leq \epsilon$ and $\left|\Delta Q_{\max }\right| \leq \epsilon$ If yes, go to step no. 6

3.Form Jacobian elements:

(a)Initialize $A[i][j]=0.0$ for $i=1$ to $2 n, j=1$ to $2 n$

(b) Form diagonal elements $H_{p p}, N_{p p}, M_{p p} \& L_{p p}$

(c) Form off - diagonal elements: $\mathrm{H}_{\mathrm{pq}}, \mathrm{N}_{\mathrm{pq}}, \mathrm{M}_{\mathrm{pq}} \& \mathrm{~L}_{\mathrm{pp}}$

(d) Form right hand side vector (mismatch vector)

$\mathrm{B}[\mathrm{i}]=\Delta \mathrm{P}[\mathrm{i}], \mathrm{B}[\mathrm{i}+\mathrm{n}]=\Delta \mathrm{Q}[\mathrm{i}]$ for $\mathrm{i}=1$ to $\mathrm{n}$ Modify the elements For $\mathrm{p}=$ slack bus; $\mathrm{H}_{\mathrm{pp}}=1 \mathrm{e} 20=10^{20}$; $\mathrm{L}_{\mathrm{pp}}=1 \mathrm{e} 20=10^{20}$;

4.Use Gauss - Elimination method for following $[\mathrm{A}][\Delta \mathrm{X}]=[\mathrm{B}]$ Update the phase angle and voltage magnitudes $\mathrm{i}=1$ to $\mathrm{n}$ For itype $=1 \& 2$, calculate $\delta_{i}=\delta_{i}+\Delta X_{i} \& \quad \mathrm{~V}_{\mathrm{i}}=\mathrm{V}_{\mathrm{i}}+\left\{\Delta \mathrm{X}_{(\mathrm{i}+\mathrm{n})}\right\} \mathrm{V}_{\mathrm{i}}$

5.One iteration over Advance iteration count $\mathrm{k}_{1}=\mathrm{k}_{1}+1$ If $\left(\mathrm{k}_{1}<\right.$ itermax) then goto step 2(b) else print problem is not converged in "itermax" iterations, Stop.

6.Print problem is converged in 'iter'no. of iterations. a)Calculate line flowsb)Bus powers, Slack bus power. C)Print the converged voltages, line flows and powers. 
Modeling of SVC: The shunt compensator SVC is simply a static capacitor/reactor with susceptance $B_{\text {svc }}$ [7]. Fig.shows the equivalent circuit of the SVC can be modeled as a shunt-connected variable susceptance $\mathrm{B}_{\mathrm{SVC}}$ at bus-i.

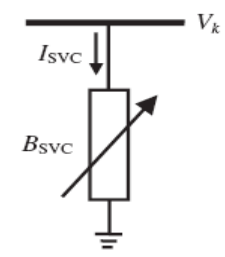

Variable shunt susceptance.

The reactive power injected into the bus due to SVC can be expressed as $\quad Q_{s v c}=B_{s v c} V^{2}$

Where $\mathrm{V}$ is the voltage magnitude of the bus at which the SVC is connected. Fig. 3.5 shows the steady-state and dynamic voltage-current characteristics of the SVC portion of the system. In the active control range, current/susceptance and reactive power is varied to regulate voltage according to a slope (droop) characteristic. The slope value depends on the desired voltage regulation, the desired sharing of reactive power production between various sources, and other needs of the system. The slope is typically $1-5 \%$. At the capacitive limit, the SVC becomes a shunt capacitor. At the inductive limit, the SVC becomes a shunt reactor (the current or reactive power may also be limited). The response shown by the dynamic characteristic is very fast (few cycles) and is the response normally represented in transient stability simulation. Some SVCs have a susceptance/current/reactive power regulator to slowly return the SVC to a desired steady-state operating point. This prevents the SVC from drifting towards its limits during normal operating conditions, preserving control margin for fast reaction during disturbances. During normal operation, voltage is not regulated unless the voltage exceeds a dead band determined by the limits on the output of the susceptance regulator.

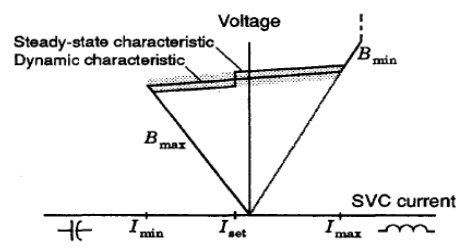

SVC static characteristics at high voltage bus.

After adding SVC at bus-i of a general power system, the new system admittance matrix $\mathrm{Y}^{\prime}$ bus can be updated as [8]:

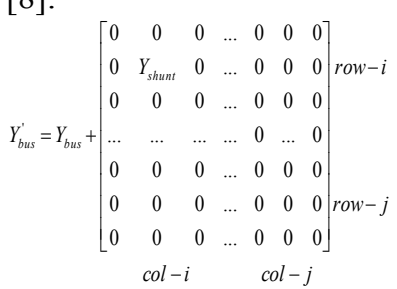

For constant active power flow and supply voltage of $\mathrm{V}_{\mathrm{rms}}$, the required capacitive $\mathrm{VAr}$ is the difference between the pre compensation VAr and the required compensated VAr as given by equation [14]:

$\operatorname{VAr}($ capacitive $)=\operatorname{VAr}($ required $)-\operatorname{VAr}($ Uncompensated $)$

The amount of the capacitive susceptance $\mathrm{B}_{\mathrm{cap}}$ is then given by Eqn.

$$
B_{c a p}=\frac{\operatorname{VAr}(\text { Required })-\operatorname{VAr}(\text { Uncompensated })}{V_{\text {ms }}^{2}} \quad \text { Siemens }
$$

From which the required capacitance value in Farad is given by using equation $\mathrm{C}($ Farad $)=\frac{B c a p}{(2 \pi f)}$

\section{Algorithm for Newton Raphson power flow Using SVC}

1.(a) Read the system line data, bus data and SVC data

Line data: From bus, to bus, line resistance, line reactance, half-line charging Susceptance and off nominal tap ratio.

Bus data: Bus no, Bus itype, $\mathrm{P}_{\text {gen, }} \mathrm{Q}_{\text {gen, }} \mathrm{P}_{\text {load, }} \mathrm{Q}_{\text {load, }}$ and Shunt capacitor data.

SVC data: SVC Bus no., variable susceptance $\left(B_{\text {svc }}\right)$

(b)Form $\mathrm{Y}_{\text {bus }}$ using sparsity technique. 
(c) Modify the $\mathrm{Y}_{\text {bus }}$ elements with the value of SVC reactance. When SVC is placed at ith bus, the modification indiagonal element as $Y_{p p}(i)=Y_{p p}(i)+y_{\text {shunt }}$

2.(a) $\mathrm{k}_{1}=1$ iteration count

(b) Set $\left|\Delta P_{\text {max }}\right|=0.0,\left|\Delta Q_{\text {max }}\right|=0.0$

(c) $\mathrm{Cal}_{\text {shed }}(\mathrm{i}), \mathrm{Q}_{\text {shed }}(\mathrm{i})$, for $\mathrm{i}=1$ to $\mathrm{n}$.

Where $P_{\text {shed }}(i)=P_{\text {gen }}(i)-P_{\text {load }}(i)$

$\mathrm{Q}_{\text {shed }}(\mathrm{i})=\mathrm{Q}_{\text {gen }}(\mathrm{i})-\mathrm{Q}_{\text {load }}(\mathrm{i})$

(d)Calculate $\mathrm{P}_{\text {cal }}(\mathrm{i})=\sum_{q=1}^{n}\left|V_{i}\right|\left|V_{q} \| Y_{i q}\right| \cos \left(\delta_{i q}-\theta_{i q}\right)$

$$
\mathrm{Q}_{\text {cal }}(\mathrm{i})=\sum_{q=1}^{n}\left|V_{i}\right|\left|V_{q} \| Y_{i q}\right| \sin \left(\delta_{i q}-\theta_{i q}\right)
$$

(e) Calculate $\Delta \mathrm{P}(\mathrm{i})=\mathrm{P}_{\text {shed }}(\mathrm{i})-\mathrm{P}_{\text {cal }}(\mathrm{i})$

$\Delta \mathrm{Q}(\mathrm{i})=\mathrm{Q}_{\text {shed }}(\mathrm{i})-\mathrm{Q}_{\text {cal }}(\mathrm{i})$ for $\mathrm{i}=1$ to $\mathrm{n}$

Set $\Delta \mathrm{P}_{\text {slack }}=0.0, \Delta \mathrm{Q}_{\text {slack }}=0.0$,

(f) Calculate $\left|\Delta P_{\max }\right|$ and $\left|\Delta Q_{\max }\right|$ form $[\Delta \mathrm{p}]$ and [ $\left.\Delta \mathrm{Q}\right]$ vectors

(g) Is $\left|\Delta P_{\max }\right| \leq \in$ and $\left|\Delta Q_{\text {max }}\right| \leq \in$ If yes, go to step no. 6

3.Form Jacobian elements:

(a) Initialize $A[i][j]=0.0$ for $\mathrm{i}=1$ to $2 \mathrm{n}, \mathrm{j}=1$ to $2 \mathrm{n}$

(b)Form diagonal elements $H_{p p}, N_{p p}, M_{p p} \& L_{p p}$ (c)Form off - diagonal elements: $H_{p q}, N_{p q}, M_{p q} \& L_{p p}$

(d) Form right hand side vector (mismatch vector)

$\mathrm{B}[\mathrm{i}]=\Delta \mathrm{P}[\mathrm{i}], \mathrm{B}[\mathrm{i}+\mathrm{n}]=\Delta \mathrm{Q}[\mathrm{i}]$ for $\mathrm{i}=1$ to $\mathrm{n}$

(e)Modifyt he elements For $\mathrm{p}=$ =slack bus; $\mathrm{H}_{\mathrm{pp}}=1 \mathrm{e} 20=10^{20} ; \mathrm{L}_{\mathrm{pp}}=1 \mathrm{e} 20=10^{20}$;

4. Use Gauss - Elimination method for following $[\mathrm{A}][\Delta \mathrm{X}]=[\mathrm{B}]$ Update the phase angle and voltage magnitudes $\mathrm{i}=1$ to $\mathrm{n}$ For itype $=1 \& 2$, calculate $\delta_{i}=\delta_{i}+\Delta X_{i} \& \quad \mathrm{~V}_{\mathrm{i}}=\mathrm{V}_{\mathrm{i}}+\left\{\Delta \mathrm{X}_{(\mathrm{i}+\mathrm{n})}\right\} \mathrm{V}_{\mathrm{i}}$

5. One iteration over Advance iteration count $\mathrm{k}_{1}=\mathrm{k}_{1}+1$ If $\left(\mathrm{k}_{1}<\right.$ itermax $)$ then goto step 2(b) else print problem is not converged in "itermax" iterations, Stop.

6.Print problem is converged in 'iter'no. of iterations. a. Calculate line flows b. Bus powers, Slack bus power. c. Print the converged voltages, line flows and powers.

\section{Case Study And Results}

IEEE 24-bus system reproduced in Fig. 4 has been used to study the implementation of the proposed GA.System data can be found in [8]. Here we represent thetwo parallel lines connected bus 1 with bus 2 as one line.Line ratings are given in appendix A. The voltagemagnitude limits of all buses are set from 0.95 to $1.1 \mathrm{pu}$

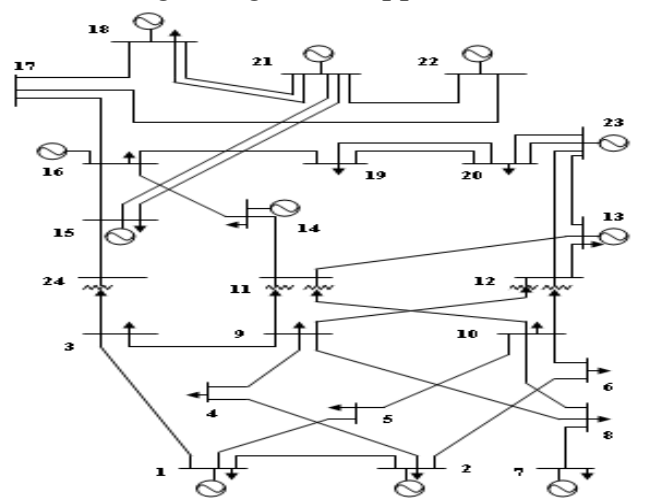

The Available Transfer Capability (ATC) are computed for a set of source/sink transfers using Continuous Power Flow (CPF). Table shows the ATCs for IEEE 24-bus system without FACTs device.

Table:-ATC without FACTS Device

\begin{tabular}{|l|l|l|}
\hline $\begin{array}{l}\text { Source/Sink bus } \\
\text { no. }\end{array}$ & ATC(M.W) & $\begin{array}{l}\text { Violation } \\
\text { Constraint }\end{array}$ \\
\hline $23 / 15$ & 770.0 & Line-24 overflow \\
\hline $22 / 9$ & 395.0 & Line-38 overflow \\
\hline $22 / 5$ & 260.0 & Line-38 overflow \\
\hline $21 / 6$ & 105.0 & Line-10 overflow \\
\hline $18 / 5$ & 260.0 & Line-38 overflow \\
\hline
\end{tabular}


The Available Transfer Capability (ATC) are computed for a set of source/sink transfers using Continuous Power Flow (CPF), when line- 8 is physically removed from the system that is connected between bus-4 and bus-9. Fig. Shows a graph voltage profile for the IEEE 24-bus system with and without outage cases.

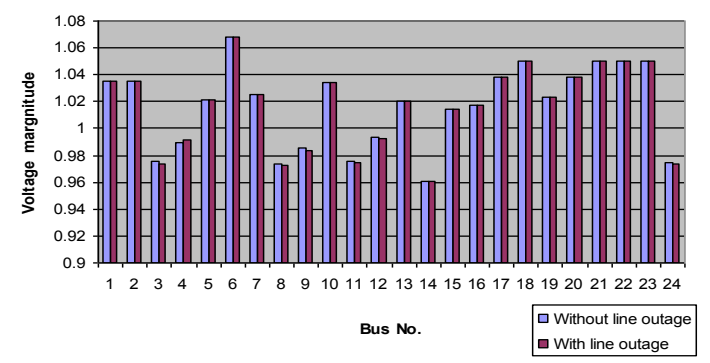

Fig:-Bus voltage profile for without and with line outage cases

\section{Conclusions}

In deregulated power systems, available transfer capability (ATC) analysis is presently a critical issue either in the operating or planning because of increased area interchanges among utilities. Sufficient ATC should be guaranteed to support free market trading and maintain an economical and secure operation over a wide range of system conditions. However, tight restrictions on the construction of new facilities due to the increasingly difficult economic, environmental, and social problems, have led to a much more intensive shared use of the existing transmission facilities by utilities and independent power producers (IPPs). Based on operating limitations of the transmission system and control capabilities of FACTS technology, technical feasibility of applying FACTS devices to boost ATCs are analyzed and identified.

\section{References}

[1] Transmission Transfer Capability Task Force, "Available transfer capability definitions and determination," North American Electric Reliability Council, NJ, June 1996.

[2] M.Noroozian, G.Anderson, "Power Flow Control by Use of Controllable Series Components", IEEE Transactions on Power Delivery, VO1.8, No.3,July 1993, 1420-1428.

[3] C.R.Fuerte-Esquivel, E.Acha, "Newton-Raphson algorithms for the reliable solution of large power networks with embedded FACTS devices", IEE Proc. Gener. Transm. Distrib., VO1.143, No.5, Sept. 1996, 447-454.

[4] G. C. Ejebe, J. Tong, J. G. Waight, J. G. Frame, X. Wang and W. F. Tinney. 1998. Available transfer capability calculations. IEEE Trans. Power Systems. 13(4): 1521-1527.

[5] 1996. North American Electric ReliabilityCouncil. Available transfer capability Definitions and determination.

[6] Wang Feng,G.B.Shrestha "Allocation of TCSC Devices to optimize Total Transmission Capacity in Competitive Power Market"IEEE Trans.Power systems,feb2001,587-592

[7] Transmission Transfer Capability Task Force,"Available transfer capability Definitions and determination", North American Electric Reliability Council,N

[8] Freris, L.L. and Sasson, A. M., Investigation on the load flow problem. Proceedings of IEE, 1968, 115, 1459-1470.

[9] IEEE Reliability Test System, IEEE transactions on power apparatus and systems, Vol.PAS-98, No.6, Nov/Dec. 1979

[10] Power Electronics in Electric Utilities: Static Var Compensators Proceedings of the IEEE, VOL. 76, NO. 4, APRIL 1988.

[11] V. Ajarapu, and C. Christie, "The continuation power flow: a practical tool for tracing power system steady state stationary behavior due to the load and generation variations," IEEE Trans. Power Systems, Vol. 7, No. 1, Feb. 1992,416-423.

[12] M.Noroozian, G.Anderson, "Power Flow Control by Use of Controllable Series Components", IEEE Transactions on Power Delivery, VO1.8, No.3, July 1993, 1420-1428.

[13] Vladimiro Miranda, J.V. Ranito, L. M. Proenca, "Genetic Algorithms in Optimal Multistage Distribution Network Planning", IEEE Trans. Power Systems, Vol. 9, o. 4, Nov. 1994, 1927-1933.

[14] Transmission Transfer Capability Task Force, "Available transfer capability Definitions and determination," North American Electric Reliability Council, NJ, June 1996.

[15] G. C. Ejebe, J. Tong, J. G. Waight, J. G. Frame, X. Wang, and W. F. Tinney, “Available transfer capability calculations," IEEE Trans. Power Systems, Vol. 13 No.4, Nov.1998, 1521-1527.

[16] Y. Dai, J. D. McCalley, V. Vittal, "Simplification, expansion and enhancement of direct interior point algorithm for power system maximum loadability", Proc. 21st Int. Conf.Power Ind. Comput. Applicat, pp. 170-179, 1999.

[17] Richard D. Christie, Bruce F. Wollenberg and Ivar Wangensteen, "Transmission Management in the Deregulated Environment", Proceedings of the IEEE, Vol.88, No.2, February 2000.

[18] Y. Xiao, Y. H. Song, Y. Z. Sun, “Available Transfer Capability Enhancement Using FACTS Devices”, Proceedings of the 2000 IEEE/PWS Summer Meeting,, Seattle, vol.1, pp. 508-515, July 2000. 


\section{BIOGRAPHIE}

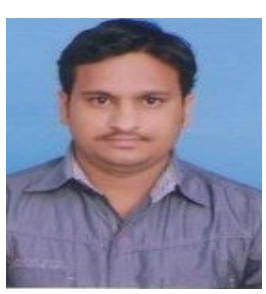

Suresh Regatti is B.Tech(Electrical) M.tech(Electrical) he is Working as a Assistant Professor at Sri Venkateshwara Engineering College ,Suryapet, nalgonda, andrapradesh, India.His research Interests in PowerElectronics,power systems Restructuring,Distributd Generation.

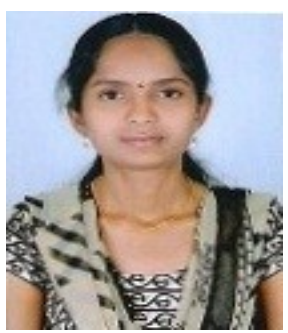

Sandhya Rani Bhooma:Post graduate student in the Department of Electrical \&Electronics Engineering at Sri Venkateshwara Engineering College, Suryapet, nalgonda, andrapradesh, India.Interested in PowerElectronics,power systems,FACTS,power system deregulation. 